\title{
Multiple cardiac rhabdomyomas: tuberous sclerosis or not?
}

\author{
Orhan Uzun, Gina McGawley, Gillian A Wharton
}

Killingbeck Hospital, Leeds

O Uzun

G A Wharton

St James's University Hospital, Leeds G McGawley

Correspondence to: Dr Orhan Uzun, Killingbeck Hospital, Department of Paediatric Cardiology, York Road, Leeds LS14 6 UO United Kingdom.

Accepted for publication 24 January 1997
A 27 year old woman with nine previous pregnancies was referred for a fetal scan. Family history revealed that her previous child and the father both had tuberous sclerosis. Tumours were detected antenatally; at 20 weeks' gestation a small mass was visible in the right ventricle and by 36 weeks' the right ventricular tumour had enlarged considerably, there were also small masses visible in the left ventricle. The rest of the pregnancy and the delivery were uncomplicated.

Postnatal examination showed a well neonate with no abnormal findings other than a soft systolic murmur in the pulmonary area. Cardiac ultrasound revealed multiple small sized tumours in the left ventricular apex, and at least four tumours in the right ventricle. The largest was a multilobed tumour located in the right ventricular apex causing mild infundibular pulmonary stenosis (figure). There were no other clinical markers of tuberous sclerosis at birth.

Six months later the child remained well, but patchy skin depigmentation typical of tuberous sclerosis had developed. His electrocardiogram was normal with no evidence of pre-excitation. Repeat echocardiogram showed good left ventricular function with regressing multiple rhabdomyomas in the left ventricle compared with the previous scan, but right ventricular masses, in particular the one in the right ventricular outflow, appeared to be larger. There was a Doppler estimated gradient of $40 \mathrm{~mm} \mathrm{Hg}$ across the pulmonary infundibulum.

\section{Discussion}

Rhabdomyoma is the most common cardiac tumour in infancy and childhood. The majority of the tumours is multiple and most frequently located in the ventricular myocardium; at least half of them have intracavitary extension. Rhabdomyoma is regarded to be a hamartoma and not capable of mitotic division after birth ${ }^{1}$; often tumour undergoes spontaneous regression postnatally. ${ }^{23}$ Treatment of rhabdomyoma is conservative, unless there are life threatening obstructions or arrhythmias surgery is not indicated. ${ }^{4}$ The diagnosis has major implications because of the strong association with tuberous sclerosis, particularly when the tumours are multiple. Detection of cardiac rhabdomyoma is now considered to be an important antenatal marker of tuberous sclerosis. ${ }^{5}$

1 McAllister HA Jr. Primary tumours of the heart and pericardium. Pathol Annu 1979;14:325-55.

2 Nir A, Taiik J, Freeman WK, Seward JB, Offord KP, Edwards WD, et al. Tuberous sclerosis and cardiac rhabdomyoma. Am f Cardiol 1995;76:419-21.

3 Farooqi ZQ, Ross RD, Paridon SM, Humes RA, Karpawich PP, Pinsky WW. Spontaneous regression of cardiac rhabdomyoma. Am f Cardiol 1991;67:897-9.

4 Foster ED, Spooner EW, Farina MA, Shaher RM, Alley RD. Cardiac rhabdomyoma in the neonate: surgical management. Ann Thorac Surg 1984;37:249-53.

5 Wallace G, Smith HC, Watson GH, Rimmer S, D'Souza SW. Tuberous sclerosis presenting with fetal and neonatal
SWrate cardiac tumours. Arch Dis Child 1990;65:377-9.
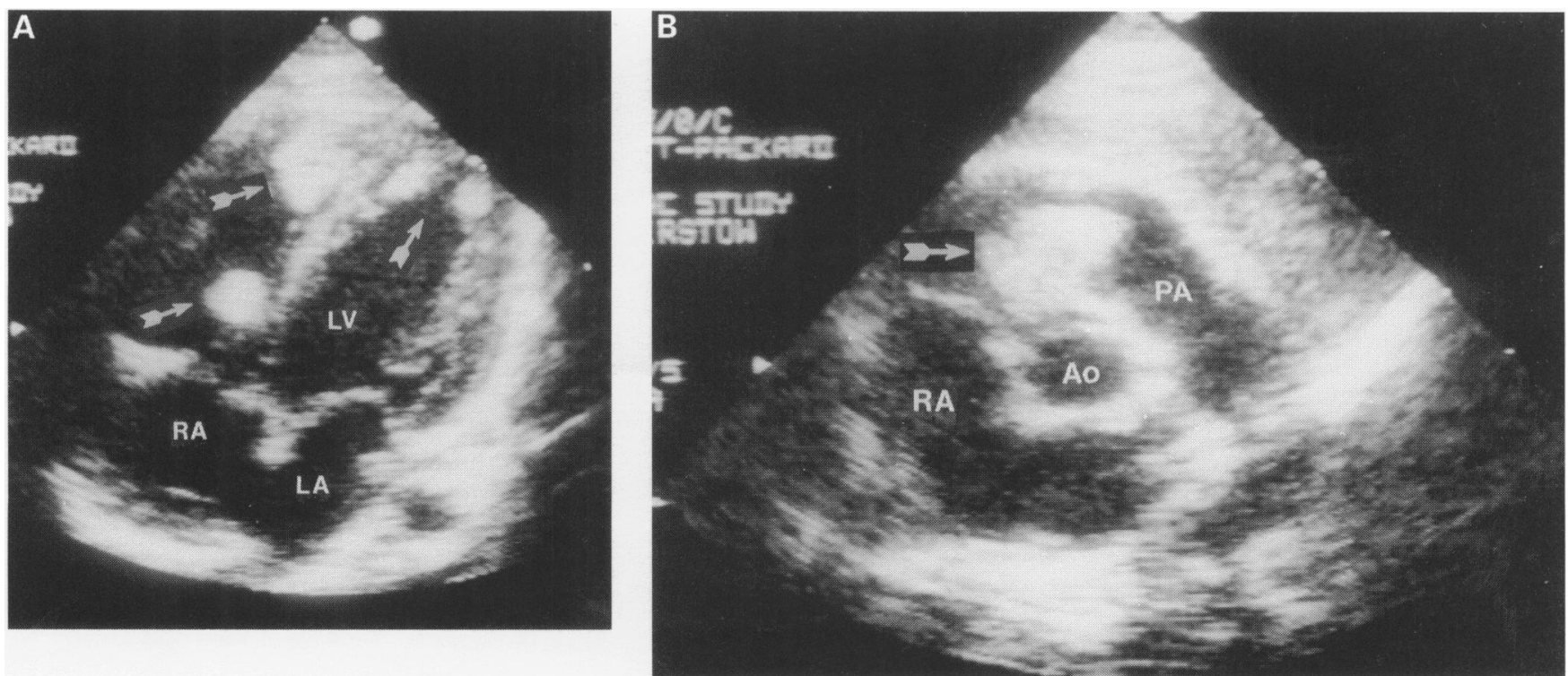

A neonatal echocardiogram $(A)$ in apical four chamber view and (B) in short axis parasternal view. Multiple rhabdomyomas (arrowed) are visible in both ventricles, the largest being multilobed and located in the right ventricular outflow tract, causing mild infundibular obstruction (peak flow velocity $2 \cdot 5 \mathrm{~m} / \mathrm{s}$ ). 